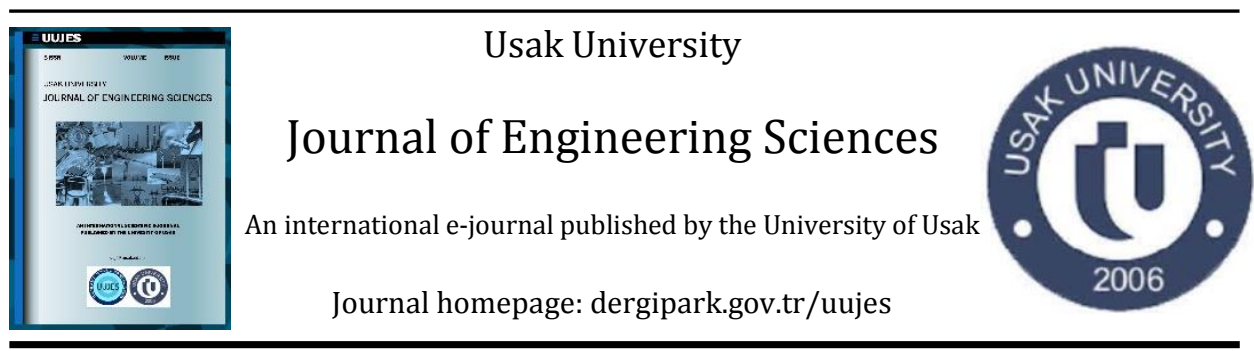

Research article

\title{
SIMULATION OF INTERNAL PIPE FLOWS IN GASOLINE PORT FUEL INJECTION SYSTEM UNDER STEADY STATE CONDITION
}

\author{
Aniekan Essienubong Ikpe ${ }^{1 *}$, Kufre Rechard Ekanem ${ }^{2}$ and Ekom Mike Etuk ${ }^{3}$ \\ ${ }^{1}$ Department of Mechanical Engineering, University of Benin, Benin City, Nigeria \\ ${ }^{2}$ Department of Physics, Akwa Ibom State Polytechnic, Ikot Osurua, Nigeria \\ ${ }^{3}$ Department of Production Engineering, University of Benin, Benin City, Nigeria
}

Received: 17 July $2021 \quad$ Revised:20 October $2021 \quad$ Accepted:09 November $2021 \quad$ Online available: 30 December 2021
Handling Co-Editor: Fulya Yllmaz

\begin{abstract}
Fluid flow models developed for pipe flow in gasoline port fuel injection system with different number of injectors working under steady state condition was simulated in this study using FLOWMASTER Software. Using existing equations, theoretical analysis were computed for the same flow parameters and results obtained for each parameter for both the simulation and theoretical approach were compared accordingly. Results obtained for the theoretical approach and that of simulation had not shown much correlation due to the assumptions and computational errors. The pipe flow was simulated under steady state condition and the inlet pressure flowing across the circular pipe was observed to increase per unit time while fluctuations characterised by sinusoidal pattern were observed on the plot of total pressure at bends against time. The normal pressure while flowing along the pipe duct increased proportionally with the pipe length but suddenly experienced a decline and pick-up again as it encountered bends. The mass flow rate of gasoline was observed to increase gradually as the simulation time progressed. For the three simulated outcomes, decrease were observed as the flow approached bends along the circular pipe. Hence, the use of FLOWMASTER software in Computational Fluid Dynamics (CFDs) helped in predicting flow characteristics along the rail pipes in gasoline port fuel injection system.
\end{abstract}

Keywords: Pressure drop, injector system, simulation, models, steady state condition.

(C)2021 Usak University all rights reserved.

\section{Introduction}

The purpose of an engine fuel system is to provide the cylinders with a mixture of air and fuel in the correct proportion at any particular instant. There are basically two methods available, one is called carburation and is used for petrol engines whereas, the other

\footnotetext{
*Corresponding author: Aniekan Essienubong Ikpe

E-mail: aniekan.ikpe@eng.uniben.edu (ORCID: 0000-0001-9069-9676)

DOI: $10.47137 /$ uujes. 972712
} 
method is a type of fuel injection which is a characteristic method for diesel engines [1]. Carburettor is a mechanical device that combines air and fuel for Internal Combustion Engines (ICEs), and operates on Bernoulli's Principle; as such, the lower the static pressure, the higher the dynamic pressure. Fuel injection is the process of introducing fuel into IC engines, through an injector. The major difference between the working principles of a carburettor and fuel injector is that fuel injector atomizes the fuel through a small nozzle under high pressure, whereas, a carburettor depends upon suction created by the air intake accelerated through a venturi tube to draw the fuel into the airstream.

In non-diesel ICEs, Gasoline Direct Injection (GDI), also referred to as spark-ignited direct injection (SIDI), Direct Fuel Injection (DFI) or Fuel Stratified Injection (FSI) is an alternative means of injecting fuel into two-stroke and four-stroke gasoline engine in recent times. Gasoline engines using DFI operates by sucking a mixture of gasoline and air into the cylinder, compressing it with a piston, and igniting it with a spark $[2,3]$. The resultant explosion from the process drives the piston downwards and generates power to maintain the car's mobility [4].

The primary function of a fuel injection system is to measure the fuel accurately and uniformly to the engine cylinders under all operating conditions from idling to full load, and fuel not injected is returned through a pressure control valve to the supply tank. Fuel from the tank is filtered before flowing to the pump, and the measured fuel is then passed to the injector which is fitted in the engine cylinder. Gasoline injection system offers a number of advantages over a carburettor type of fuel system such as; increased engine power; precise metering of fuel to each cylinder and increased air flow which can result in more horsepower output.

Fuel injector system provides better control of mixture enrichment than carburettor, lower emissions, lean efficient air-fuel mixture, reduces exhaust pollution and improves atomization. Fuel is forced into the intake manifold under pressure and that helps break fuel droplets into a fine mist, better fuel distribution and uniform flow of fuel vapours into each cylinder $[5,6]$. A typical fuel injection system incorporates fuel filter, fuel pump, injectors, fuel pressure control valves, pressure transducer, air temperature manifold, starter motor switch, idling air control valve (throttle bypass), cooling water transducer etc. [7].

Pressure loss is as a result of pressure drop and it is also due to the difference in pressure between two points in a flow system [8,9]. It arises from frictional force caused by resistance to flow, and acts on the fluid as flow progresses across the channel such as duct, which could be internal or external [10]. Gasoline injector system simulation modelling in recent times have been used as an effective tool for evaluating engine operation and performance. Thermodynamic models for conventional diesel engine cycle have also been used as effective tools for detailed analysis of engine performance [11,12].

Flow computation of total head loss and total pressure loss in a typical gasoline fuel injector system was theoretically conducted by Orhorhoro et al. [13]. The minor head losses were caused by frictional loss due to bends and changes in pipe diameter. However, for major head loss such as pressure loss, it was caused frictional loses in the pipes due to fluid flow in attempt to overcome shear viscous resistance resulting from shear and normal forces in the pipe internal surface. It was observed that a drop in pressure led to decrease in thrust as well as increase in specific fuel consumption. 
Cardosa [14] investigated port fuel injection strategies for a lean burn gasoline engine. It was observed that different fuel injection strategies generated different levels of fuel concentration. It was identified that fuel injection in a single port created fuel stratification in the spark plug area but were more prone to cycle to cycle variations in fuel concentration. Split phased injection increased the combustion stability of lean mixtures in the low load and low speed areas. It showed potentials to improve fuel efficiency in the typical engine operating range of city driving.

Amber [15] applied an electronic fuel injection system to a single cylinder, four-stroke cycle gasoline engine. The engine was tested for maximum wide open throttle torque and power values with the electronic fuel injection system installed. The tests were conducted with a fixed injector pulse width and an open loop control strategy. A closed loop strategy was then developed and tested under a variety of fuel injection timing settings and lambda sensor target values. Fuel injection resulted in torque and horsepower improvements at all engine speeds, with approximately $20 \%$ torque and horsepower increase at top engine test speed.

Kotena [16] investigated an injection fuel system, performance and emission as well as simulation of engine cold flow process in order to determine the in-cylinder flow characteristics of single-cylinder, 5lt DI diesel engine. Pressure and temperature distributions indicated that turbulence is driven by combustion effect. Increased pressure offered good mixture of the air and fuel within the cylinder. Pre-combustion structure was observed to vaporized fuel droplets by means of high temperature and ensured controlled combustion and emission.

Numerical simulation of a piezo-actuated common rail injector fluid-mechanical model was employed by Koten et al. [17] to investigate the effects of injector parameters on fuel flow. Injection cycle took place in nearly 1 millisecond while poppet movement and velocity formed within this interval. The poppet lift was about $0.22 \mathrm{~mm}$ and attained 875 $\mathrm{m} / \mathrm{s}$ of maximum velocity at the opening and closing phase. Due to the behaviour of fuel flow, maximum velocity occurred in closing movement of the poppet, thereby, minimizing the rate of fuel consumption. Mass and volumetric flow rates had maximum values of 0.055 $\mathrm{kg} / \mathrm{s}$ and $0.0625 \mathrm{~L} / \mathrm{s}$, indicating fuel density of $0.88 \mathrm{~kg} / \mathrm{L}$.

El-Adawy et al. [18] experimentally studied the in-cylinder flow in Gasoline Direct Injection (GDI) engine head at different valve lifts, under steady-state conditions using Particle Image Velocimetry (PIV). It was observed that at low valve lifts (1 to $5 \mathrm{~mm}$ ), 48.9 to $46.6 \%$ of the flow energy is concentrated in the large (mode 1 ) eddies, 8.4 to $11.46 \%$ in mode 2 and 7.2 to 7.5 in mode 3. At high valve lifts, some energy in the large eddies of mode 1 was transferred to the smaller flow structure of modes 2 and 3 . This was clearly observed in 10 $\mathrm{mm}$ valve lift where the values of the flow energy were $40.6 \%, 17.3 \%$, and $8.0 \%$ for modes 1,2 , and 3.

Mandokhot [19] developed a predictive gasoline direct fuel injector model to predict instantaneous flow rate and corresponding instantaneous needle lift during operation. The needle rise during low pressure condition occurred faster than that obtained in the experiment, indicating inappropriate electromagnetic force modelling or incorrect damping characterization. At a larger time duration of the injection process, prediction in cumulative flow by the model felled short of the averaged experimental results at the current injection process. This is because the errors in steady state flow due to different pressure pulsations inside the injector became dominant. 
The needle lift predicted by the model indicated distinct zones of rise, bounce, steady, fall and closure dribble. It was observed that if the interval between two injection events is short, the needle in the first event may not have reached full closure before the next injection event has been actuated. A better understanding of gasoline port fuel injection in terms of the number of injectors required for optimum performance is an important aspect of achieving improved fuel delivery and in-cylinder combustion performance.

This goes along with understanding the flow characteristics, as to be able to determine if the working condition of the injectors or the flow behaviour is in line with the expected condition. This has always been achieved through different experimental procedures depending on the data desired. However, some of the procedure is time consuming and very expensive particularly when complex equipment are required for measurement, taking of readings and generating data for analysis. While the data may not be accurate if the equipment are not accurately calibrated during the experimental process, performing hydraulic calculations or computing the data on a spreadsheet may be an error-prone process.

In recent times, the application of Computational Fluid Dynamics (CFDs) tools have been employed in fluid dynamics to predict the patterns of fluid flow and their characteristics along pipes, orifices, ducts etc. Studies have shown that the validation of experimentally generated data with data generated by some conventional CFD tools such as FLOWMASTER always correlate with little or no error [20]. This can generate more accurate results similar to what is obtained in real life scenarios while also providing a reliable prediction of flow rates in order to improve in-cylinder combustion performance. Hence, FLOWMASTER version 7.0 was employed in this study to determine the flow characteristics along the rail pipes of a gasoline port fuel injection system with different number of injectors working under steady state condition.

\section{Materials and Method}

Gasoline injector system models were developed using FLOWMASTER version 7.0. The software incorporates a Model-Based Design (MBD) and Simulation-Based Characterization (SBC) features that allow modeling of components for which data is either difficult to obtain, or non-existent in a 1D platform, to be created. In this study, the simulated models were developed for certain working conditions such as two injectors working in steady state simultaneously, one injector working in steady state condition and four injectors working simultaneously. Theoretical calculations were also carried out to determine the various flow characteristics within the gasoline injection system and were compared with two injectors working in steady state simultaneously. The simulation results for all the models developed at certain flow conditions were also compared with each other.

FLOWMASTER is a multipurpose 1D CFD tool that has a wide range of applicability in modeling, simulation and analysis of fluid behavior in complex piping systems and ducting channels at any given scale. It is a thermo-fluid system that has a large capacity to perform flow simulation for liquids and gases, heat and mass transfer, moving bodies, two-phase flow and Fluid Structure Interactions (FSI) through Computational Modelling Algorithms (CMA). It uses a method of characteristic solver that allows it to accurately model fluid transients in complex systems and systems-of-systems such as pressure surge.

The solver has embedded "parametric" for design iterations and a Structured Query Language (SQL) rational database to accommodate and track all models, results, and 
performance data. A number of tools can enable FLOMASTER to be integrated with product development tools and systems, including optimization tools such as Optimus, Control Modeling tools such as Simulink and other Computer Aided Engineering (CAE) tools. Integration is enhanced through an embedded script editor which allows creation of native macros, scripts and plug-ins. FLOWMASTER is user friendly and offers the following advantages:

i. Hydraulic calculations for a number of element types, from pipes and open duct channels to drop inlets and weirs.

ii. Solve for any unknown property.

iii. Design for any desired characteristics.

iv. Produce detailed reports and rating curves.

v. FLOWMASTER improves design productivity, ultimately saving project costs.

vi. It minimizes computational resources and execution times at the system level.

vii. Delivers higher accuracy results than standalone 1D CFD.

viii. Upfront and concurrent design of equipment from component to system level for fluid flow and heat transfer.

ix. Allows for easy reuse of the characterized component.

$\mathrm{x}$. Virtual prototyping to reduce cost and lead time.

xi. Deploy simulation throughout your lifecycle to planned maintenance, refit, retrofit or expansion.

xii. Operates on standard engineering hardware.

xiii. Allows for easy reuse of the characterized component.

xiv. Provides meaningful results faster and allows more "what-if" scenarios to be run.

$\mathrm{xv}$. Relieves time pressures when a design must be finished quickly.

xvi. Allows better management and problem-solving for complex system designs.

xvii. Brings a more complete solution to the hands of system engineers.

\subsection{Parameters and assumptions}

i. $\quad$ Working fluid $=$ Gasoline

ii. Temperature $=15.6^{\circ} \mathrm{C}$

iii. Injectors working simultaneously are $=\mathrm{A} \& \mathrm{C}$

iv. Surface roughness of steel pipes $=\mathrm{Ks}=0.045 \mathrm{~mm}$

v. $\quad \mu=$ dynamic viscosity $=0.00029 \mathrm{Kg} / \mathrm{ms}$

vi. Flow was assumed to be steady and incompressible

Assuming the system is a closed cycle, the fuel discharge rate $Q$ was obtained using Equation 1:

$Q=\rho V A$

Where, $\rho$ is the density of air $\left(\mathrm{kg} / \mathrm{m}^{3}\right), \mathrm{V}$ is the flow velocity $(\mathrm{m} / \mathrm{s})$ and A is the cross sectional area of connecting pipes. Cross sectional area of the connecting pipes was calculated using Equation 2:

$A=\frac{\pi d^{2}}{4}$

The Reynolds number (Re) is given in Equation 3:

$R e=\frac{V D}{v}=\frac{\rho V D}{\mu}$ 
Where, $v$ is the dynamic viscosity $\left(\mathrm{m}^{2} / \mathrm{s}\right), \mu$ is the kinematic viscosity of gasoline given as $1.895 \times 10^{-5} \mathrm{~kg} / \mathrm{m}$. s, $\rho$ is the density for gasoline given as $744.7168 \mathrm{~kg} / \mathrm{m}^{3}$. Equation 4 was used to determine the major head losses at bends in the pipe.

$$
h_{\text {lmajor }}=f(R e) \times \frac{L}{D} \times \frac{v^{2}}{2 g}
$$

To determine the minor head losses at bends in the pipe, Equation 5 was used:

$h_{l \text { minor }}=K_{l} \times \frac{V^{2}}{2 g}$

The friction factor was considered as expressed in Equation 6:

Friction factor $(f)=\frac{0.25}{\left[\log _{3.7 D} \frac{k}{R e^{0.9}}\right]^{2}}$

Equation 7 was used in calculating the total head loss at $90^{\circ}$ bends

Total head loss $=h_{\text {lmajor }}+h_{\text {lminor }}$

Pressure loss was calculated using the Equation 8:

$\Delta P=\rho g h_{l(\text { total })}$

Equation 9 and 10 were used to determine the volume flow rate through the injection nozzle:

$Q=\frac{C_{d} A}{\sqrt{1-\beta^{4}}} * \sqrt{\frac{2 \Delta P}{\rho}}$

Where $\beta=\frac{\text { Injection diameter }}{\text { Pipe diameter }}$

$C_{d}$ is the coefficient of discharge. Equation 11 was used to find the inlet static pressure by hand calculation:

$P_{o}=P_{\text {inlet static }}+0.5(\rho V 2)$

Where, $\mathrm{C}_{\mathrm{d}}$ is the coefficient of discharge, $P_{o}$ is the total inlet pressure (Pa), $P$ (inlet static) is the inlet static pressure $(\mathrm{Pa}), \rho$ is the density of air $\left(\mathrm{kg} / \mathrm{m}^{3}\right)$ and $\mathrm{V}$ is the inlet velocity $(\mathrm{m} / \mathrm{s})$.

\subsection{Simulated flow models}

Figs. 1-4 represent flow models developed for the injection system under steady state condition. The flow models were developed using FLOWMASTER software version 7.0. The Figures illustrate models of rail pipe framework in gasoline port fuel injection system with different numbers of injector working under steady condition at a time. 


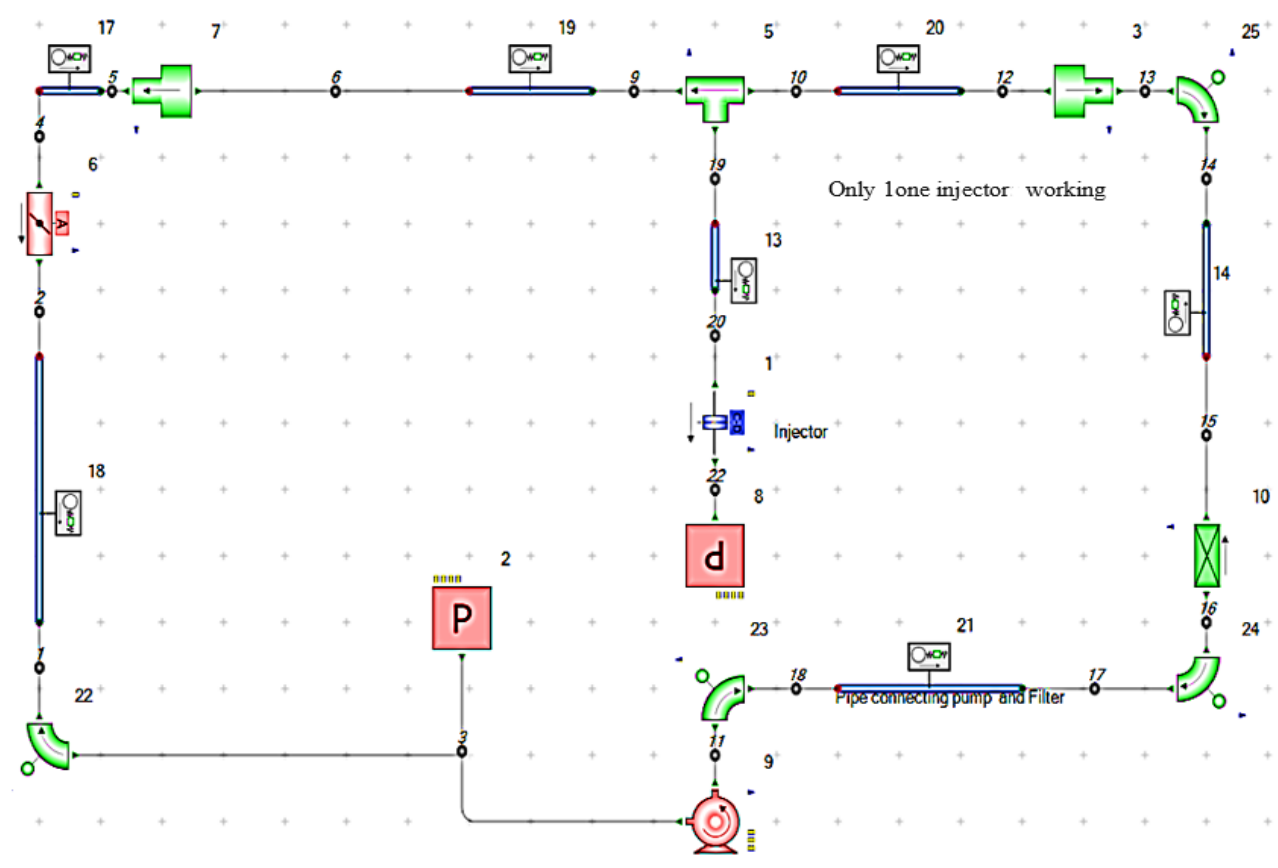

Fig. 1 Illustrates of model with one injector working

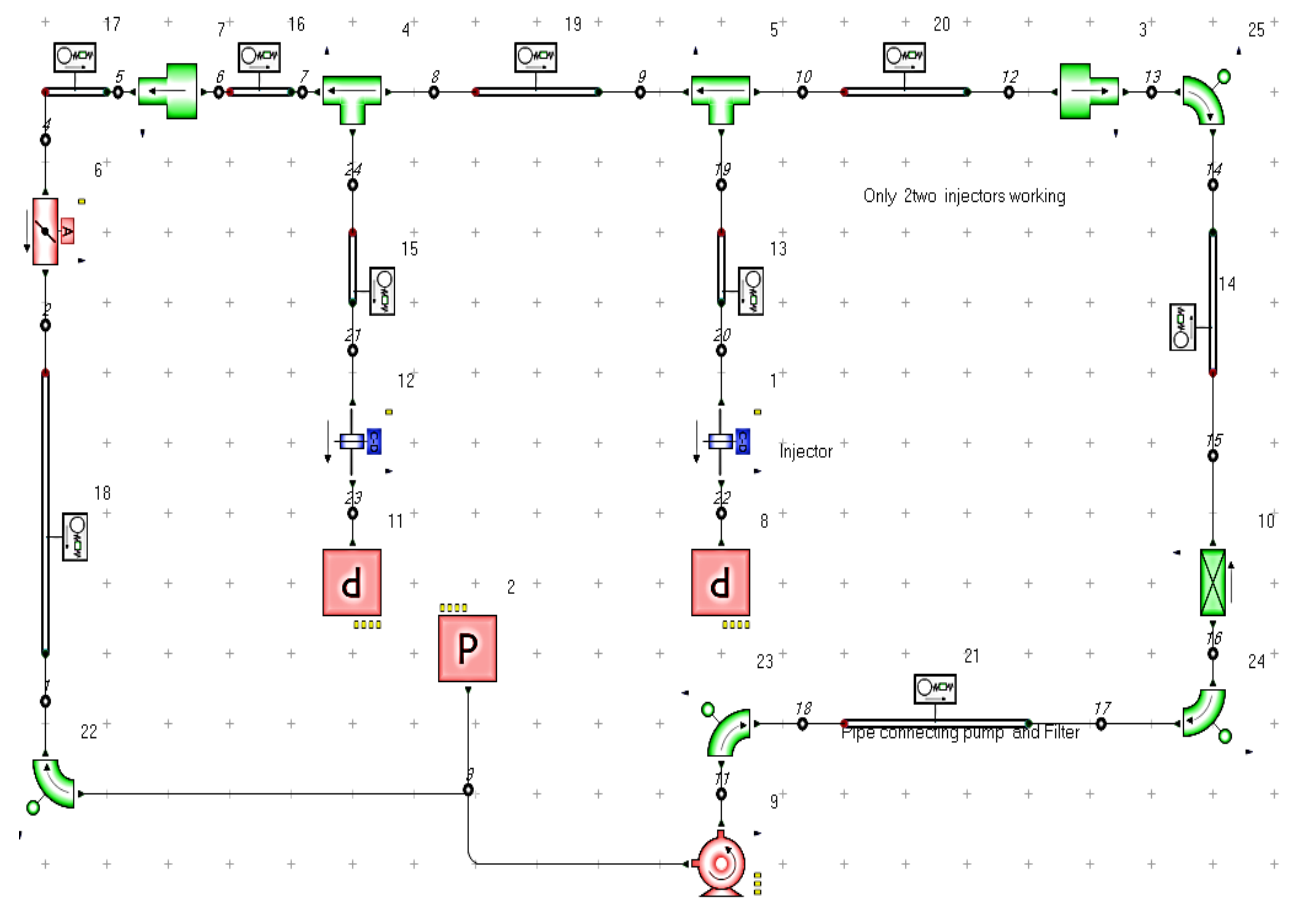

Fig. 2 Illustrates of model with two injectors working 


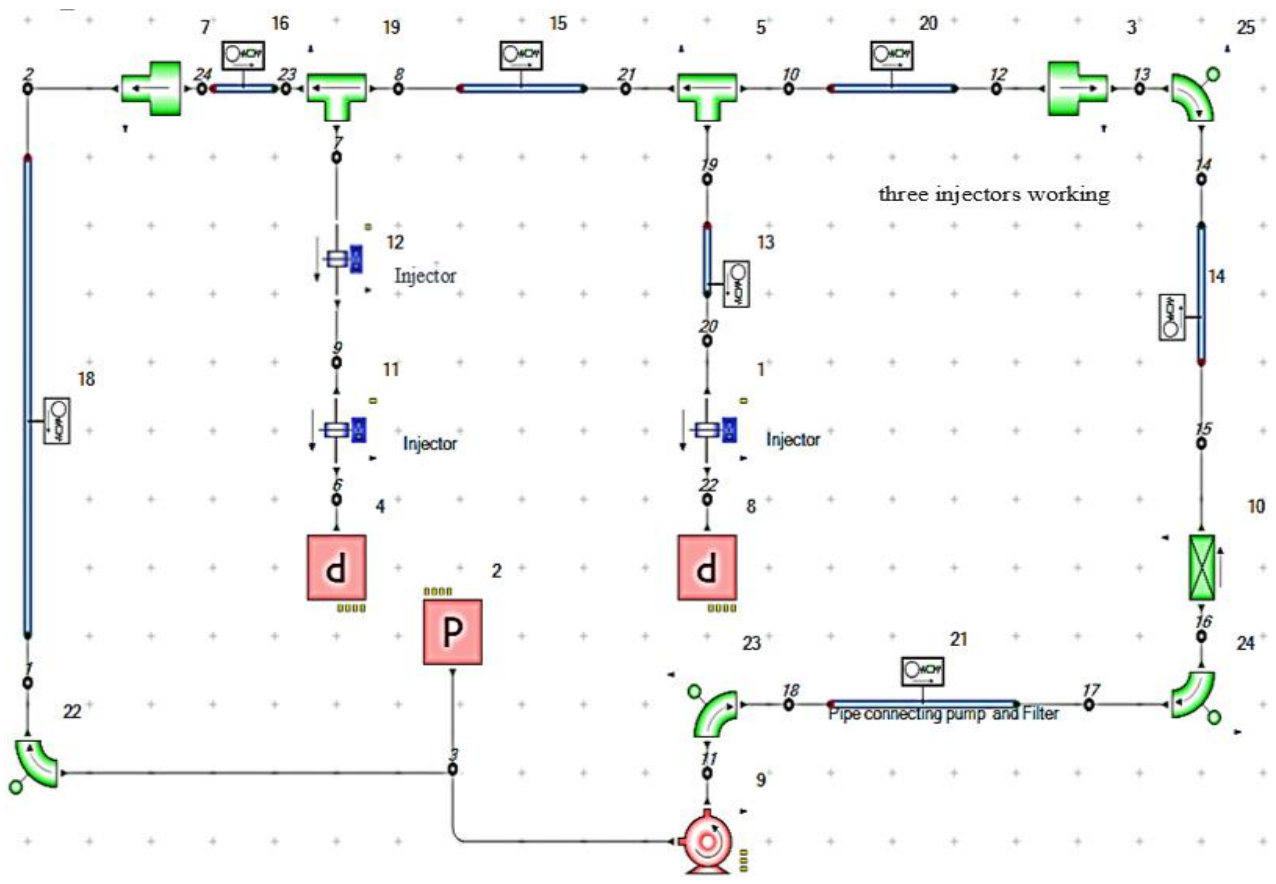

Fig. 3 Illustrates of model with three injectors working

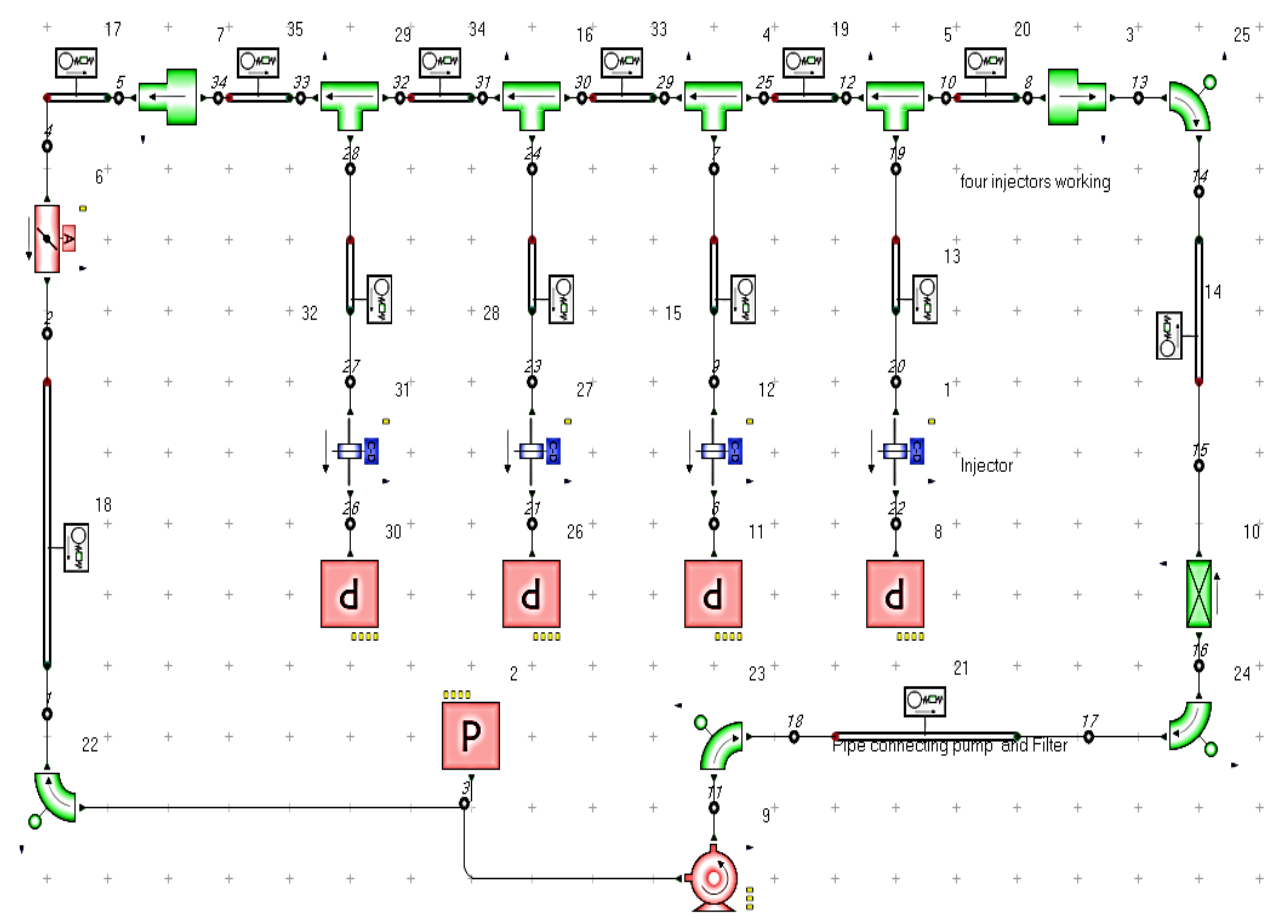

Fig. 4 Illustrates of model with four injectors working 


\section{Results and discussion}

One-Dimensional fluid flow models were developed in FLOWMASTER software environment for the injection system under steady state condition and analysed to compare the theoretical calculation to the analysis carried out using FLOWMASTER software. Table 1 summarizes the results obtained by theoretical calculations and the results obtained from FLOWMASTER software.

Table 1. Comparison between hand calculation and FLOWMASTER results

\begin{tabular}{|c|c|c|c|}
\hline $\mathbf{S} / \mathbf{N}$ & Flow Characteristics & $\begin{array}{l}\text { Theoretical } \\
\text { Calculations } \\
\text { (pressure drop) } \\
\text { bar }\end{array}$ & $\begin{array}{l}\text { FLOWMASTER } \\
\text { Analysis } \\
\text { (pressure drop) } \\
\text { bar }\end{array}$ \\
\hline 1 & $\begin{array}{l}\text { Pressure drop in the pipe from pump to } \\
\text { filter }\end{array}$ & 0.417 & 0.531 \\
\hline 2 & Pressure loss in the filter & 0.0241 & 0.0226 \\
\hline 3 & $\begin{array}{l}\text { Pressure drop between the filter and } \\
\text { common rail pipe }\end{array}$ & 0.0299 & 0.0318 \\
\hline 4 & Total pressure drop in the common rail & 0.0023 & 0.0016 \\
\hline 5 & Pressure drop in the injector pipe & 0.0072 & 0.0079 \\
\hline 6 & $\begin{array}{l}\text { Pressure drop due to sudden expansion } \\
\text { between pipes coming from filter to } \\
\text { common rail pipe }\end{array}$ & 0.078 & 0.083 \\
\hline 7 & $\begin{array}{l}\text { Pressure drop due to sudden } \\
\text { contraction from common rail pipe to } \\
\text { the return pipe }\end{array}$ & 0.0018 & 0.0021 \\
\hline 8 & $\begin{array}{l}\text { Pressure drop between pressure } \\
\text { regulator and common rail pipe. }\end{array}$ & 0.022 & 0.031 \\
\hline 9 & Pressure drop in the return pipe & 0.038 & 0.041 \\
\hline 10 & $\begin{array}{l}\text { Pressure drop connecting from fuel } \\
\text { pump to filter }\end{array}$ & 0.167 & 0.159 \\
\hline 11 & pressure drop in one injector & 2.27 & 3.07 \\
\hline 12 & Total pump pressure drop & 3.12 & 2.53 \\
\hline
\end{tabular}

As shown in Table 1, the results determined by theoretical calculations and FLOWMASTER analysis did not show strong agreements due to different facts; universal constants and assumption that were been made. Some of the assumptions made includes temperature of the fuel and flow friction coefficients which were inputted during the calculation and analysis. The corner flow bending factors for $90^{\circ}$ has positive impacts on the incompressible fluid flow to cause pressure drop. The models developed were also simulated for operating conditions with different number of injectors. Table 2-5 represents the results of fluid flow model working with one, two, three and four injectors. The parameters simulated includes inlet pressure, normal pressure, flow velocity, mass flow rate, turbulent intensity and the total pressure at bends respectively. 
Table 2. Results of fluid flow model with one injector working

\begin{tabular}{ccccccc}
\hline Time & $\begin{array}{c}\text { Inlet } \\
\text { pressure }\end{array}$ & $\begin{array}{c}\text { Normal } \\
\text { pressure }\end{array}$ & $\begin{array}{c}\text { Flow } \\
\text { velocity }\end{array}$ & $\begin{array}{c}\text { Mass } \\
\text { flow rate }\end{array}$ & $\begin{array}{c}\text { Turbulence } \\
\text { intensity }\end{array}$ & $\begin{array}{c}\text { Total pressure } \\
\text { at bends }\end{array}$ \\
\hline 1 & 4.2 & 18.3 & 3.16 & 0.4 & 0.29881 & 7.2 \\
2 & 9.1 & 10.2 & 5.34 & 0.7 & 0.29881 & 5.6 \\
3 & 14.3 & 25.4 & 8.75 & 1.2 & 0.29881 & 12.3 \\
4 & 18.2 & 15.1 & 13.48 & 1.5 & 0.29881 & 10.4 \\
5 & 25.4 & 36.8 & 19.61 & 1.8 & 0.29881 & 17.7 \\
6 & 32.7 & 21.2 & 24.27 & 2.3 & 0.29881 & 15.1 \\
7 & 36.8 & 32.7 & 31.31 & 2.5 & 0.29881 & 24.2 \\
\hline
\end{tabular}

Table 3. Results of fluid flow model with two injector working

\begin{tabular}{ccccccc}
\hline S/N & $\begin{array}{l}\text { Inlet } \\
\text { pressure }\end{array}$ & $\begin{array}{l}\text { Normal } \\
\text { pressure }\end{array}$ & $\begin{array}{l}\text { Flow } \\
\text { velocity }\end{array}$ & $\begin{array}{l}\text { Mass } \\
\text { flow rate }\end{array}$ & $\begin{array}{l}\text { Turbulence } \\
\text { intensity }\end{array}$ & $\begin{array}{l}\text { Total pressure } \\
\text { at bends }\end{array}$ \\
\hline 1 & 6.2 & 25.4 & 5.36 & 2.8 & 0.29881 & 14.6 \\
2 & 12.1 & 17.2 & 7.24 & 3.3 & 0.29881 & 9.2 \\
3 & 16.4 & 34.6 & 12.65 & 3.5 & 0.29881 & 18.4 \\
4 & 26.1 & 21.1 & 18.28 & 3.9 & 0.29881 & 16.6 \\
5 & 32.6 & 44.4 & 24.31 & 4.2 & 0.29881 & 27.3 \\
6 & 41.3 & 30.1 & 31.47 & 4.4 & 0.29881 & 24.5 \\
$\mathbf{7}$ & 44.4 & 41.3 & 36.81 & 4.7 & 0.29881 & 39.2 \\
\hline
\end{tabular}

Table 4. Results of fluid flow model with three injectors working

\begin{tabular}{ccccccc}
\hline S/N & $\begin{array}{l}\text { Inlet } \\
\text { pressure }\end{array}$ & $\begin{array}{l}\text { Normal } \\
\text { pressure }\end{array}$ & $\begin{array}{l}\text { Flow } \\
\text { velocity }\end{array}$ & $\begin{array}{l}\text { Mass } \\
\text { flow } \\
\text { rate }\end{array}$ & $\begin{array}{l}\text { Turbulence } \\
\text { intensity }\end{array}$ & $\begin{array}{l}\text { Total Pressure } \\
\text { at bends }\end{array}$ \\
\hline 1 & 8.2 & 31.6 & 7.23 & 4.8 & 0.29881 & 18.3 \\
2 & 15.3 & 22.4 & 8.25 & 5.0 & 0.29881 & 11.2 \\
3 & 19.2 & 38.7 & 14.62 & 5.2 & 0.29881 & 24.1 \\
4 & 30.4 & 26.3 & 23.12 & 5.5 & 0.29881 & 19.4 \\
5 & 36.6 & 43.5 & 27.31 & 5.7 & 0.29881 & 33.5 \\
6 & 46.1 & 33.6 & 33.15 & 5.9 & 0.29881 & 28.5 \\
7 & 52.5 & 46.1 & 38.21 & 6.1 & 0.29881 & 42.6 \\
\hline
\end{tabular}

Table 5. Results of fluid flow model with four injectors working

\begin{tabular}{ccccccc}
\hline S/N & $\begin{array}{l}\text { Inlet } \\
\text { pressure }\end{array}$ & $\begin{array}{l}\text { Normal } \\
\text { pressure }\end{array}$ & $\begin{array}{l}\text { Flow } \\
\text { velocity }\end{array}$ & $\begin{array}{l}\text { Mass } \\
\text { flow rate }\end{array}$ & $\begin{array}{l}\text { Turbulence } \\
\text { intensity }\end{array}$ & $\begin{array}{l}\text { Total Pressure } \\
\text { at bends }\end{array}$ \\
\hline 1 & 12.4 & 36.4 & 10.3 & 6.2 & 0.29881 & 23.2 \\
2 & 18.5 & 27.7 & 16.23 & 7.9 & 0.29881 & 15.3 \\
3 & 24.7 & 42.5 & 22.26 & 8.2 & 0.29881 & 29.6 \\
4 & 34.8 & 33.3 & 30.32 & 8.7 & 0.29881 & 22.5 \\
5 & 40.3 & 48.8 & 38.61 & 9.1 & 0.29881 & 40.4 \\
6 & 49.1 & 37.6 & 46.52 & 9.6 & 0.29881 & 33.1 \\
7 & 62.6 & 54.1 & 53.18 & 10.0 & 0.29881 & 57.8 \\
\hline
\end{tabular}

Fig. 5 represents a plot of total pressure at bends and inlet pressure of gasoline against time. It indicates that the inlet pressure flowing across a circular pipe presented in this study increased per unit time, whereas, fluctuations characterised by sinusoidal pattern is observed on the plot of total pressure at bends against time. In the absence of leakage, 
barriers or bends, the inlet pressure is supposed to increase constantly as shown in Fig 5, until a constant pattern is observed when the flow stabilizes.

However, due to the presence of bends and the nature of the pipe geometry, the total pressure of gasoline decreased from the inlet or normal pressure for every $5 \mathrm{~s}$ and increased again after the pressure force build momentum. From the kinetic theory of gas, the pressure of gas flowing in a pipe is in constant random motion, where the gas molecules collide with each other, the walls of the pipe and producing forces perpendicular and tangential to the walls of the pipe. Summation of the forces of all the gas molecules divided by the area of the pipe walls is known as the gas pressure, which is a measure of the average linear momentum of the moving molecules of the gas [21, 22].

Fig. 6 represents a plot of normal pressure against total pressure at bends for four different injectors. From the plot, the normal pressure obtained for using one injector ranges from 18.3 to 32.7 bar, 25.4 to 41.3 bar for two injectors, 31.6 to 46.1 bar for three injectors and 36.4 to 54.1 bar for four injectors. The normal pressure in this case is defined as the pressure flowing along the duct of the pipe, and it varies with the inlet pressure. The normal pressure while flowing along the pipe duct increased with the pipe length as it travels but suddenly experienced a decline and picks up again as it encountered a bend. This phenomenon can also occur due to unforeseen vibration of the pipe configuration which may interrupt the flow for some time and causing delay in the incoming flow, afterwards, pressure of the delayed flow rushes back rapidly to the peak value [23].

Fig. 7 shows the plot of mass flow rate against time. This is the mass of gasoline flowing through the pipe per unit time, and depends on the density, velocity of the fluid and the sectional area of the pipe. From the plot, it can be observed that the mass flow rate of gasoline which is the working fluid selected in this study increased gradually as the time progressed. Furthermore, it is also observed that the flow rate increased as the number of injectors also increased. Therefore, maximum flow rate of $10 \mathrm{~kg} / \mathrm{s}$ at $35 \mathrm{~s}$ was obtained from using four injectors while minimum flow rate of $2.5 \mathrm{~kg} / \mathrm{s}$ at $35 \mathrm{~s}$ was obtained from using one injector. As discussed earlier the mass flow rate is likely to drop when the flow encounter bends and when the pressure drops as a result of leakage or when the pipe clogs.

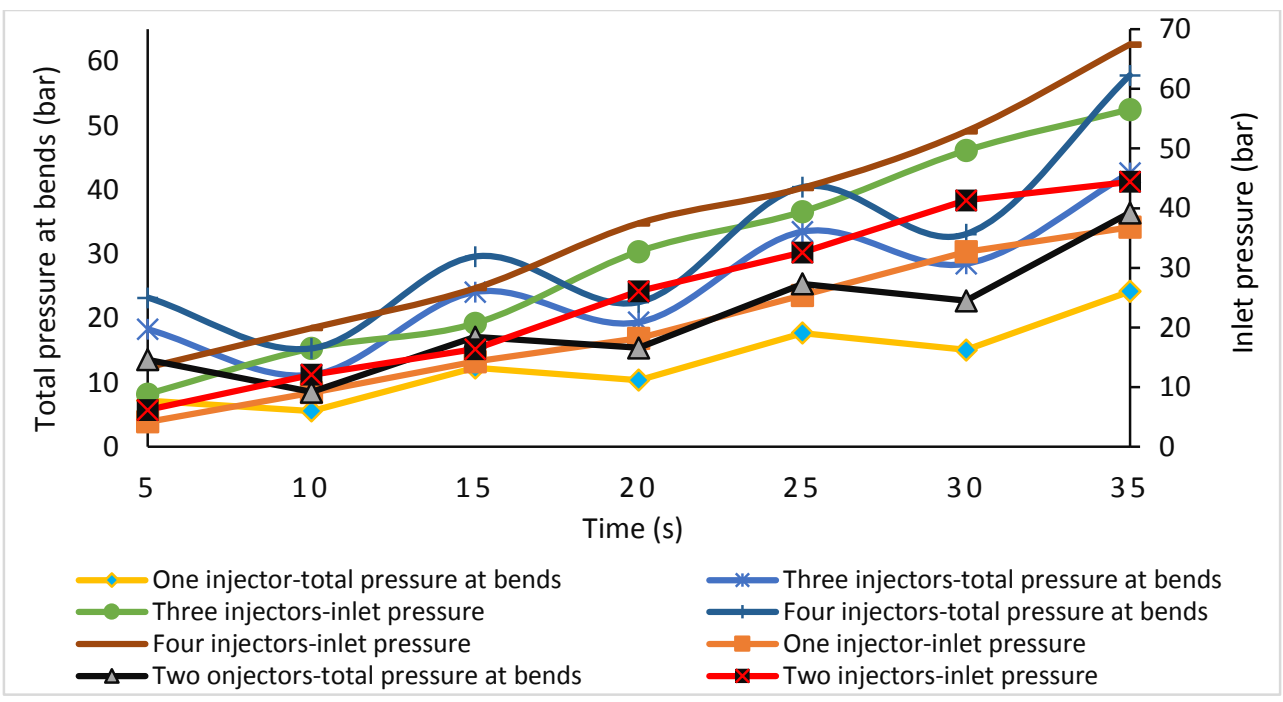

Fig. 5 Plot of total pressure at bends and inlet pressure against time 


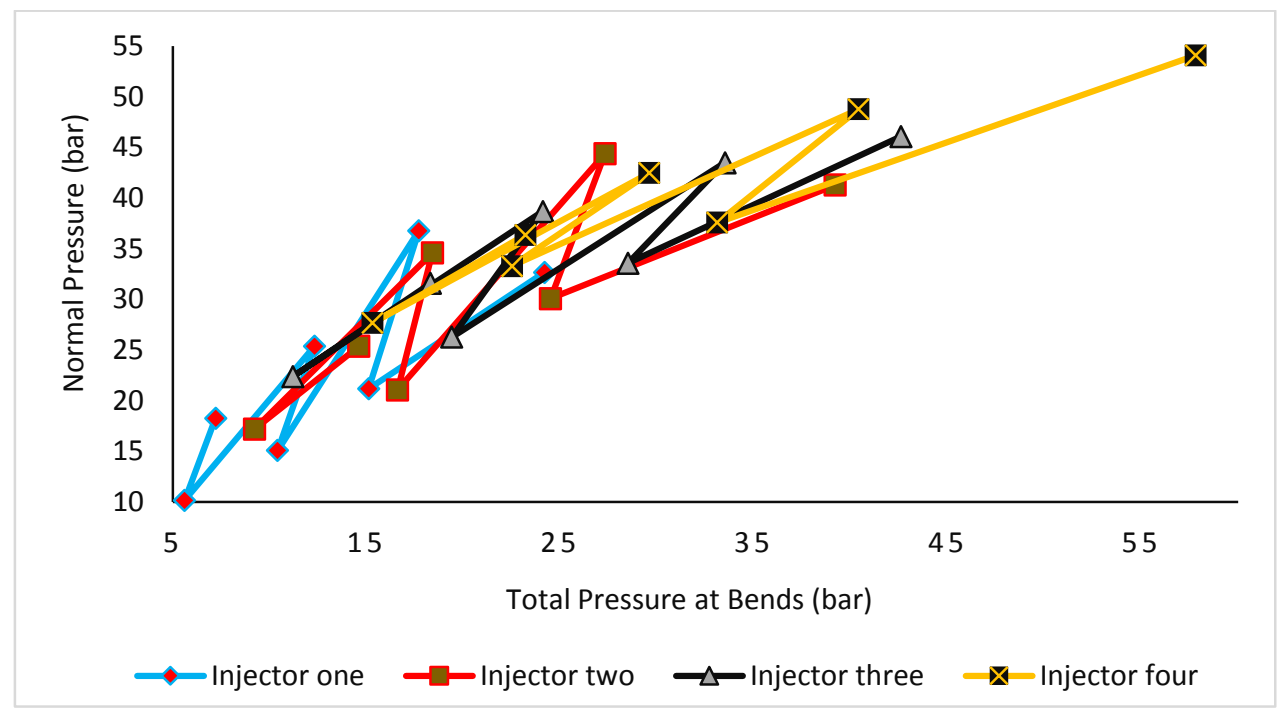

Fig. 6 Plot of flow velocity against time

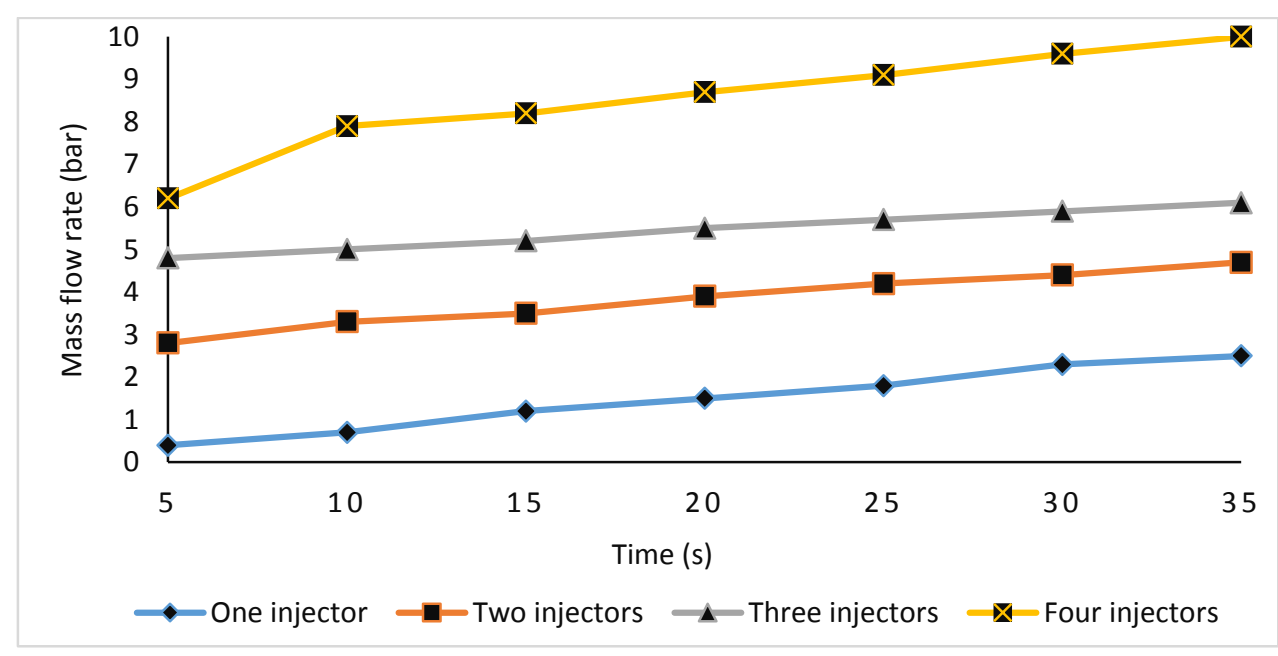

Fig. 7 Plot of mass flow rate against time

Simulation of pipe flows in gasoline port fuel injection system under steady state condition revealed the occurrence of two flow patterns namely: turbulent and laminar flow. When flow is turbulent, the layers mix together causing significant velocity in the directions other than the actual flow directions. Therefore, turbulent flow is a flow regime characterized by chaotic property changes such as rapid pressure variations as well as flow velocity in space and time.

As shown in Fig 8, turbulent is characterized by fluid flow in which layers of the fluid intermixes via eddies and swirls. In this case, pipe geometries prone turbulence are elbows and sharp bends, of which turbulence occur by imparting velocities perpendicular to the flow along the pipes. Also, turbulence in the piping system may be due to the speed at which the product travels per unit area of the pipe. The drag between adjacent layers of 
the fluid and between the fluid and its surroundings can cause swirls and eddies (see Fig 8 ) if the flow speed is not controlled [24, 25].

However, Laminar flow or streamline flow in pipes or tubes occur in layers without mixing or when fluid flows in parallel layers without disruption between the layers as shown in Fig 9. At low velocities, the fluid tends to flow without lateral mixing and adjacent layers slid pass each other in the process. Therefore, cross current perpendicular to flow direction, eddies or swirls of fluid does not occur. That is because, motion of the fluid particles flow in a straight line parallel to the pipe walls, and any form of parallel mixing (mixing at right angles to the flow direction) occurs as a result of diffusion between layers of the liquid. However, diffusion mixing can occur at a slow rate if the pipe diameter is small, otherwise, it can be significant.

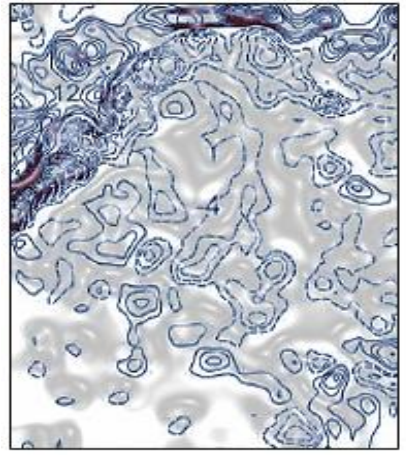

(a)

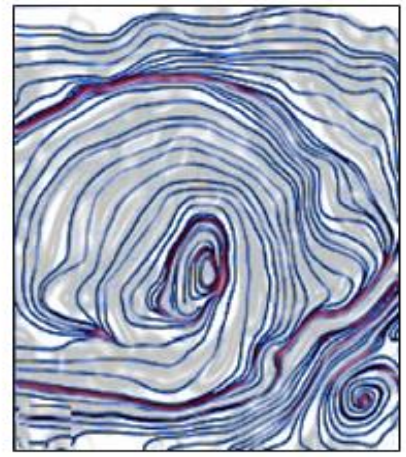

(b)

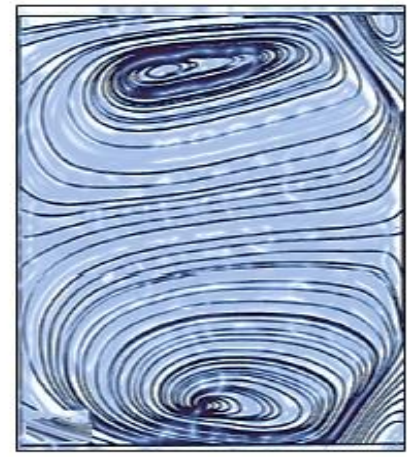

(c)

Fig. 8 Characteristic of turbulent flow in injector rail pipe

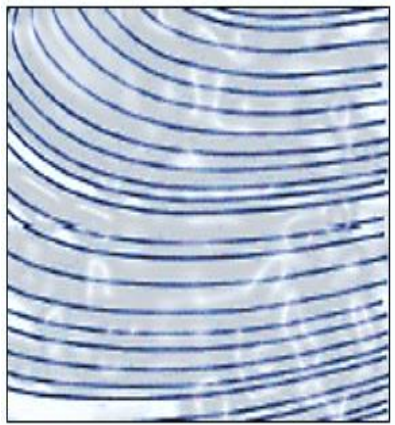

(a)

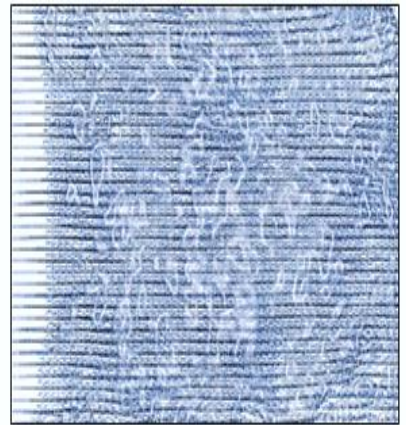

(b)

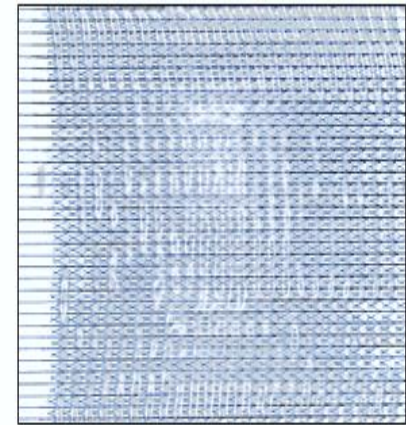

(c)

Fig. 9 Characteristics of laminar flow in injector rail pipe

\section{Conclusion}

Internal pipe flows in gasoline port fuel injection system under steady state condition was successfully simulated in this study using FLOWMASTER software version 7.0 and theoretically computed by hand calculation. The variations between simulated results and theoretically computed results were within the limit of tolerance, indicating that computer aided tools such as FLOWMASTER software can be applied in the prediction of internal flows with minimal errors. Based on the four criteria used in the simulation, the conclusion of this study was drawn based on the observation that normal pressure under steady state condition is higher than the total pressure at bends and the inlet pressure while the total 
pressure at bends is higher than the inlet pressure. Also, the inlet pressure, normal pressure and the total pressure flowing across the pipes were observed to increase with the number of injectors used. This is also applicable to the mass flow rate and the flow velocity of the gasoline flowing across the pipe. The mass flow rate of gasoline across the system for each injector also increased with increasing simulation time. Flow patterns in the rail pipes were characterized by both laminar (flow at low velocities and in parallel layers) and turbulent (fluid layers intermixes via eddies and swirls) flows.

\section{References}

1. Krishna TK, Shouri K and Kumar RD. Design and Analysis of Electronic Fuel Injector of Diesel Engine. Int. J. of Sci. \& Eng. Res., 2013; 4(10): 1070-1076.

2. Baumgarten C. Mixture Formation in Internal Combustion Engines. Springer Berlin Heidelberg, ISBN: 9783540308355, 2006.

3. Kumaravel K, Saravanan GG and Premanand B. Experimental Studies on the Comparison of Static Fuel Injection Characteristics of Fuel Injectors Used in GDI Engine. Int. J. of Adv. Sci. and Tech. Res., 2014; 4(1): 419-432.

4. Gold A. Direct Fuel Injection: The and how of the fuel Delivering Technology. https://www.thoughtco.com/direct-fuel-injection-533861, 2017.

5. Chang WS, Kim YN and Kong JK. Design and Development of a Central Direct Injection Stratified Gasoline Engine, SAE Paper 01-3531, 2007.

6. Hardenberg HO. The Middle Ages of the Internal Combustion Engine. US: Soc. of Auto. Eng., 1999.

7. Cengel Y, Cimbala J, Turner R and Kanoglu M. Thermo-Fluid Sciences. McGrawHill, Newyork, 2012.

8. McConkey A and Eastop TD. Applied Thermodynamics for Engineering Technologists, Fifth Edition, Pearson Education, ISBN: 9788177582383, 2012.

9. Schmid M, Leipertz A and Fettes C. Influence of Nozzle Hole Geometry, Rail Pressure and Pre-Injection on Injection, Vaporization and Combustion in a Singlecylinder Transparent Passenger Car Common rail Engine. SAE Paper No: 200201-2665, 2002.

10. Walker IS, Wray CP, Dickerhoff DJ and Sherman MH. Evaluation of Flow Hood Measurements for Residential Register Flows. LBNL 47382, 2001.

11. Rakopoulos CD and Giakoumis EG. Simulation and analysis of a naturally aspirated, indirect injection diesel engine under transient conditions comprising the effect of various dynamic and thermodynamic parameters. Eng. Conv. \& Mgt., 1997; 39(5/6): 465-484.

12. Rakopoulos CD and Giakoumis EG. Second-Law Analysis of Indirect Injection Turbocharged Diesel Engine Operation under Steady-State and Transient Conditions. SAE International 2005-01-1131, 2005.

13. Orhorhoro EK, Ikpe AE and Yohannan O. (2016) Flow Computation of Total Head Losses and Total Pressure Losses in a Typical Gasoline Fuel Injector System. Int. Aca. J. of Sci. and Eng., 2016; 3(10): 30-47.

14. Cardosa TPL. Port Fuel Injection Strategies for a Lean Burn Gasoline Engine. Thesis: University of Brighton, 2011.

15. Amber GM. Application of an Electronic Fuel Injection System to a Single Cylinder, Four-Stroke Cycle Gasoline Engine. Thesis: University of Rhode Island, Paper 1156, 1995. 
16. Koten H. Performance Analysis of a Diesel Engine within a Multi-Dimensional Framework. J. of Therm. Eng., 2018; 4(4): 2075-2082.

17. Koten H, Gunes EC and Guner K. Piezo-actuated Common Rail Injector Structure and Efficient Design. J. of Ene Sys., 2018; 2(3): 97-114.

18. El-Adawy M, Heikal MR, Aziz AR, Siddiqui MI and Munir S. (2017) Characterization of the Inlet Port Flow under Steady-State Conditions Using PIV and POD. Eng., 2017; 10(1950): 1-16.

19. Mandokhot MA. Development of Predictive Gasoline Direct Fuel Injector Model for Improved In-cylinder Combustion Characterization. Thesis: The Ohio State University, 2018.

20. Zhang Q, Wu F, Yang Z, Li G and Zuo J. Simulation of the Transient Characteristics of Water Pipeline Leakage with Different Bending Angles. Water, 2019; 11(1871): 2-15.

21. Ikpe AE and Orhorhoro EK. Pressure Losses Analysis in Air Duct FlowUsing Computational Fluid Dynamics (CFD). Int. Aca. J. of Sci. and Eng., 2016; 3(9): 5570.

22. Ikpe AE, Orhorhoro EK and Ogiemudia OG. Computational Fluid Dynamics (CFD) Simulation in Air Duct Channels Using STAR CCM+. Eur. J. of Adv. in Eng. and Tech., 2017; 4(3): 216-220.

23. Iluobe IC, Ikpe AE and Imonitie DI. Modelling and Simulation of High Pressure Fogging Air Intake Cooling Unit of Omotosho Phase II Gas Turbine Power Plant. J. of App. Res. on Ind. Eng., 2020; 7(2): 121-136.

24. Ikpe AE, Owunna IB and John PO. (2021) Port Flow Simulation and In-cylinder Swirl Motion Characteristic Effects in Internal Combustion Engine Duty Cycle. App. of Mod. and Sim., 2021; 5: 102-114.

25. Ikpe AE and Owunna IB. A 3D Modelling of the In-Cylinder Combustion Dynamics of Two Stroke Internal Combustion Engine in Its Service Condition. Nig. J. of Tech., 2020; 39(1): 161-172. 